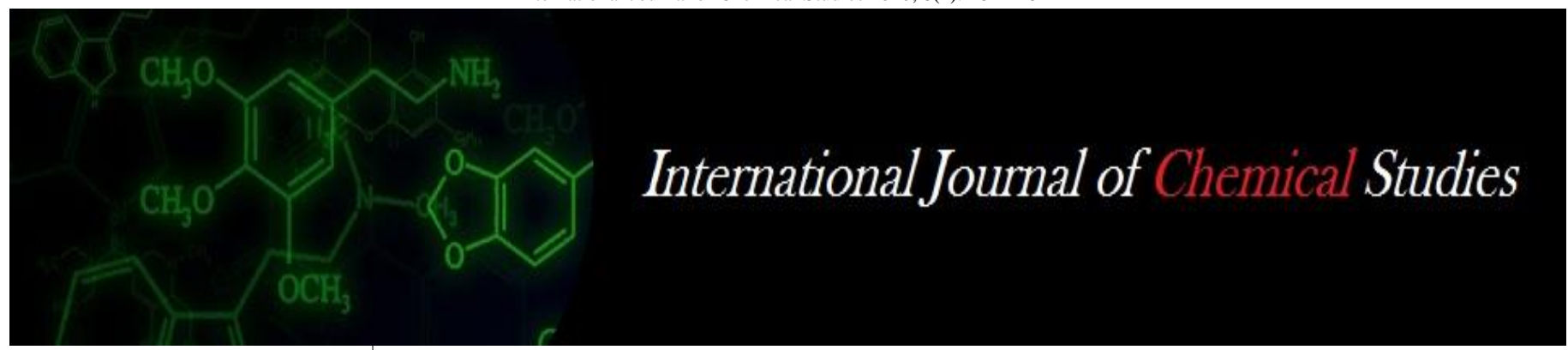

P-ISSN: 2349-8528

E-ISSN: 2321-4902

www.chemijournal.com

IJCS 2020; 8(4): 2814-2821

(C) 2020 IJCS

Received: 25-05-2020

Accepted: 27-06-2020

\section{Shashibhushan}

Senior Scientist, Seed Research

and Technology Centre,

PJTSAU, Hyderabad,

Telangana, India

UG Patel

Research Scientist, Agricultural

Research Station, Surath,

Gujarat, India
Corresponding Author: D Shashibhushan

Senior Scientist, Seed Research and Technology Centre,

PJTSAU, Hyderabad,

Telangana, India

\title{
Genetic evaluation of conventional, GMS and CMS based hybrids in upland cotton (Gosypium hirsutum L.)
}

\section{Shashibhushan and UG Patel}

DOI: $\underline{\text { https://doi.org/10.22271/chemi.2020.v8.i4ag.10071 }}$

\section{Abstract}

Cotton is one of the most momentous and important cash crops exercising profound influence on economics and social affairs of the world. It is also called White Gold. The present investigation was conducted with 52 Gosypium hirsutum entries comprising of $42 \mathrm{~F}_{1}$ s produced by Conventional (14 $\left.\mathrm{F}_{1} \mathrm{~s}\right)$, GMS(14 $\left.F_{1} s\right)$ and CMS(14 $\left.F_{1 s}\right)$ method, by using same 7 females and 2 males and 1 check were evaluated at three locations viz., Surat, Bharuch and Hansot. The experiment was laid out in a Randomized Complete Block design (RBD) with three replications. Analysis of variance showed significance difference among the characters. The s.c.a. variances were greater than g.c.a. variances for Plant height, number of sympodia per plant, number of monopodia per plant, number of bolls per plant, boll weight, ginning percentage, seed yield per plant, 2.5 per cent span length and fibre length except days to 50 per cent flowering, seeds per boll and seed index, indicating the non-additive gene effects, thus, it emphasizes the use of heterosis breeding approach to exploit available vigour in this crop. The parents, G (B) 20 was found to be good general combiner for all the traits except plant height and ginning percentage and average combiner for days to 50 per cent flowering, seed index and fibre strength, whereas, LRK-516 was found to be good general combiner for all the traits except ginning percentage and average combiner for 2.5 per cent span length and number of bolls per plant. Therefore, these two parents were noted as good source of favorable genes for increasing seed cotton yield through various yield contributing characters.

Keywords: Cotton, additive, non-additive, G.C.A, S.C.A and good combiners

\section{Introduction}

Cotton, the king of the fibre, also called White Gold. To meet the challenges of increasing productivity, Gossypium hirsutum L. offers better scope for genetic improvement among the four-cultivated species of cotton. Majority of cotton produced by G. hirsutum species is medium and long staple. This species has very high adaptability with rich diversity for yield and yield related characters. India is pioneer country in commercial exploitation of heterosis in cotton by developing several interspecific and intraspecific, hybrids for general cultivation. These cover nearly 40 per cent of cotton growing area and contribute 40-45 per cent to the national production. However, at present the hybrid cotton seed is being produced by cumbersome and laborious process of hand emasculation and pollination. Probably this single largest factor has affected its further expansion and its production is not within the means of average farmer. To overcome the high cost of hybrid cotton seed, use of male sterility (as in sorghum, pearl milletetc.) Could be the only answer in eliminating labour intensive manual emasculation. Use of male sterile lines appears to be advantageous since the maintenance of male sterile population for seed production is easier and more over sterility source under reference is stable. Cytoplasmic nuclear interaction affect the petal size and anther number which can be used as markers in identifying the parental lines and for ascertaining genetic purity.

At present the only stable and dependable CGMS source under various environment is of $G$. harknessii which in interaction with genome of $G$. hirsutum produces male sterility. A single dominant gene 'Rf' from $G$. harknessii is essential for fertility restoration and fertility enhancement factor from barbadense. Information on the presence of commercially exploitable heterosis within the available conventional, GMS and CGMS lines, their general 
combining ability and stability of resultant cross combinations is highly useful in evolving early maturing and high yielding stable hybrids.

\section{Materials and Methods}

The present investigation was conducted with 52 Gosypium hirsutum entries comprising of $42 \quad \mathrm{~F}_{1} \mathrm{~s}$ produced by Conventional (14 $\left.\mathrm{F}_{1} \mathrm{~s}\right)$, GMS $\left(14 \quad \mathrm{~F}_{1} \mathrm{~s}\right)$ and $\operatorname{CMS}\left(14 \quad \mathrm{~F}_{1} \mathrm{~s}\right)$ method by using same 7 females and 2 males and 1 check were evaluated at three locations viz., Surat, Bharuch and Hansot. The experiment was laid out in a Randomized Complete Block design (RBD) with three replications. The parents and $F_{1}$ s with standard checks were represented by a single row plot of 14 plants, placed at $120 \mathrm{~cm} \mathrm{x} 45 \mathrm{~cm}$. All the agronomical practices and plant protection measures were followed as and when required to raise a good crop of cotton. The seeds of these parents were obtained from Main Cotton Research Station, Surat. For obtaining the cross seeds, parents were grown at Main Cotton Research Station, Surat. All the $\mathrm{F}_{1} \mathrm{~S}$ and selfed seeds of parents were stored properly in thick paper bags for sowing in the next season at three locations.

\section{Results \\ Analysis of variance for combining ability}

Analysis of variance revealed highly significant difference among the parents and hybrids for the all the characters in all three location, indicating the presence of presence of genetic diversity among them (Table 1a to 1c).

\section{Combining ability effects}

The estimates of general combining ability (g.c.a) effects of parents and specific combining ability (s.c.a) effects of crosses for different characters are presented in Table $2 \mathrm{a}$ to 2c. The salient features of the results of g.c.a. and s.c.a. effects for different characters are given below.

\section{Days to 50 per cent flowering}

Earliness being a desirable character, the parents PH 93, LRK 516 and G.Cot.10; PH 93, LRA 5166, LRK 516 and G.Cot.10; and PH 93, LRK 516 and G.Cot.10 showed significant and negative g.c.a. effects in conventional, GMS and CMS methods respectively in pooled analysis.

The estimates of specific combining ability effects revealed that 76 IH 20 x DHY 286-1, LH 900 x DHY 286-1 and LRK 516 x G.Cot.10; LH 900 x DH 286-1, LRK 516 x G.Cot.10 and 76 IH 20 x DHY 286-1; and LH 900 x DHY 286-1 and G(B) 20 x G.Cot.10 recorded significant and negative s.c.a. effects in all three methods, respectively.

\section{Plant height (cm)}

An examination of g.c.a. estimates revealed that parents LH 900, LRA 5166, LRK 516 and DHY 286-1 had significant and negative g.c.a. effects in all the three methods in pooled data.

Significant s.c.a. effects in desired direction were exhibited by hybrids viz., LRA 5166 x G.Cot.10, LRK 516 x G.Cot.10, G(B) 20 x DHY 286-1 and G.Cot.100 x DHY 286-1; 76 IH 20 x G.Cot.10, LH 900 x G.Cot.10, PH 92 x G.Cot.10, LRA 5166 x G.Cot.10 and G(B) 20 x DHY 286-1; and 76 IH 20 x DHY 286-1, LH 900 x G.Cot.10, LRA 5166 x G.Cot.10 and G(B) $20 \times$ DHY 286-1 in conventional, GMS and CMS systems, respectively.

\section{Number of monopodia per plant}

Parents LRA 5166 and LRK 516; 76 IH 20, LRK 516 and G.Cot.10; LRK 516 and G(B) 20 manifested significant and positive g.c.a. effects in the conventional, GMS and CMS methods, respectively.

The estimates of s.c.a. effects revealed that in conventional method 76 IH 20 x G.Cot.10, LH 900 x DHY 286-1, PH 93 x G.Cot.10, LRA 5166 x G.Cot.10, LRK 516 x DHY 286-1, G(B) 20 x G.Cot.10 and G.Cot.100 x DHY 286-1; in GMS method LH 900 x G.Cot.10, PH 93 x G.Cot.10, LRA 5166 x DHY 286-1 and G(B) 20 x G.Cot.10; and in CMS method 76 IH 20 x G.Cot.10, PH 93 x G.Cot.10, LRA 5166 x DHY 2861 and LRK 516 x DHY 286-1 showed significant and positive s.c.a. effects.

\section{Number of sympodia per plant}

Based on estimates of g.c.a. effects, it was observed that $G(B)$ 20 and G.Cot.100;, LRK 516, G(B) 20 and G.Cot.100; and G(B) 20, G.Cot.100 and DHY 286-1 exhibited significant positive g.c.a. effects in the three methods viz., conventional, GMS and CMS, respectively.

An estimates of s.c.a. effects of crosses revealed that five, three and three hybrids recorded significant and positive s.c.a. effects in conventional, GMS and CMS method, respectively. The best three hybrids with significant and positive s.c.a. effects were LRA 5166 x G.Cot.10, LRK 516 x DHY 286-1 and 76 IH $20 \times$ DHY 286-1 in conventional method, whereas PH 93 x G.Cot.10, LRK 516 x DHY 286-1 and LH 900 x DHY 286-1 in GMS method, while G.Cot.100 x G.Cot.10, PH 93 x DHY 286-1 and LRK 516 x DHY 286-1 in CMS method.

\section{Number of bolls per plant}

The estimates of g.c.a. effects of parents revealed that LRA 5166 and G(B) 20, DHY 286-1; 76 IH 20, LRA 5166 and G(B) 20, DHY 286-1; and PH 93, G(B) 20 and DHY 286-1 exhibited significant and positive g.c.a. effects in all the three methods.

A perusal of estimates of s.c.a. effects of hybrids revealed that the hybrids viz., LH $900 \times$ G.Cot.10, PH 93 x G.Cot.10, LRA 5166 x DHY 286-1, LRK 516 x DHY 286-1, G(B) 20 x G.Cot.10 and G.Cot.100 x G.Cot.10 in conventional method, hybrids viz., LH 900 x DHY 286-1, PH 93 x G.Cot.10, LRA 5166 x G.Cot.10, LRK 516 x DHY 286-1, G(B) 20 x G.Cot.10 and G.Cot.100 x DHY 286-1 in GMS method; and hybrids viz; 76 IH 20 x DHY 286-1, PH 93 x DHY 286-1, G(B) 20 x G.Cot.10, G.Cot.100 x DHY 286-1 in CMS method exhibited significant positive s.c.a. effects.

\section{Boll weight (g)}

An examination of general combining ability effects of parents revealed that LH 900, LRK 516, G(B) 20, G.Cot.100 and G.Cot.10; LRA 5166, G(B) 20 and G.Cot.10; and LH 900, LRK 516, G(B) 20 and G.Cot.100 recorded significant and positive gca effects in all the three methods, respectively. Among the 42 hybrids, six, five and six hybrids recorded significant and positive s.c.a. effects in conventional, GMS and CMS methods, respectively. The three superior hybrids in each system were 76 IH 20 x DHY 286-1, LH 900 x DHY 286-1 and G.Cot.100 x G.Cot.10 in conventional system; G.Cot.100 x G.Cot.10, 76 IH 20 x DHY 286-1 and LH 900 x DHY 286-1 in GMS system; and G.Cot.100 x G.Cot.10, G(B) 20 x DHY 286-1 and LRA 5166 x G.Cot.10 in CMS system. 


\section{Number of seeds per boll}

The estimates of g.c.a. effects of parents revealed that LRA 5166, G(B) 20 and DHY 286-1; LRK 516, G(B) 20, G.Cot.100 and DHY 286-1; and G(B) 20, G.Cot.100 and DHY 286-1 recorded significant and positive g.c.a. effects in the conventional, GMS and CMS methods, respectively in pooled analysis.

Among 42 hybrids, LRA 5166 x G.Cot.10, LRK 516 x DHY 286-1, G(B) 20 x G.Cot.10 ; and 76 IH 20 x DHY 286-1, LH 900x DHY 286-1, PH 93 x G.Cot.10, PH 93 x DHY 286-1, G.Cot.100 x G.Cot.10 ; and LRA 5166 x G.Cot.10, G(B) 20 x DHY 286-1, G.Cot.100 x G.Cot.10 showed significant and positive s.c.a. effects in the conventional, GMS and CMS method, respectively.

\section{Seed index (g)}

The parents LRK 516, G.Cot.100;LRK 516, G.Cot.100 ; and G(B) 20, G.Cot.100, DHY 286-1, recorded positive and significant gca effects inconventional, GMS and CMS methods, respectively.

A perusal of s.c.a. effects revealed that the conventional hybrids viz., 76 IH 20 x G.Cot.10, LH 900 x DHY 286-1 and LRK 516 x G.Cot.10; the GMS based hybrids viz; 76 IH $20 \mathrm{x}$ DHY 286-1, LRA 5166 x G.Cot.10 and G(B) 20 x G.Cot.10; and the CMS based hybrids viz; 76 IH 2 x DHY 286-1, LH $900 \times$ DHY 286-1, PH 93 x G.Cot.10 and LRA 5166 x G.Cot.10 exhibited significant and positive s.c.a. effects.

\section{Ginning percentage $(\%)$}

The estimates of g.c.a. effects of parents revealed that PH 93, 76 IH 20 ; PH 93 ; and PH 93 , LRK 516 recorded significant and positive g.c.a. effects in all three systems viz., conventional, GMS and CMS method, respectively.

The estimates of specific combining ability effects revealed that the conventional hybrids viz; PH 93 x DHY 286-1, LRA 5166 x G.Cot.10, LRK 516 x DHY 286-1, G(B) 20 x G.Cot.10 and G.Cot.100 x DHY 286-1; the GMS based hybrids viz; 76 IH 20 x DHY 286-1, LH 900 x DHY 286-1, PH 93 x G.Cot.10, G(B) 20 x G.Cot.10 and G.Cot.100 x DHY 286-1; and in CMS based hybrids viz; LRK 516 x G.Cot.10, G(B) 20 x DHY 286-1 and G.Cot.100 x DHY 286-1 exhibited significant and positive sca effects for ginning percentage.

\section{Seed cotton yield per plant (g)}

The perusal of estimates of g.c.a. effects of parents revealed that LRA 5166, G(B) 20 ; LRK 516, G(B) 20, DHY 286-1 ; and LRK 516, G(B) 20, G.Cot.100, DHY 286-1 exhibited significant and positive g.c.a. effects.

The estimates of s.c.a. effects of hybrids revealed that among the 42 hybrids, six hybrids of each method (conventional, GMS and CMS) exhibited significant and positive s.c.a. effects. The best three hybrids in conventional method were LRK 516 x DHY 286-1, LH 900 x DHY 286-1 and LRA 5166 x G.Cot.10 ; whereas in GMS method were LH 900 x DHY 286-1, LRA 5166 x G.Cot.10 and LRK 516 x DHY 286-1; and while in CMS method were G(B) $20 \times$ G.Cot.10, LRK 516 x DHY 286-1 and LRA 5166 x G.Cot.10.

\section{Per cent span length (mm)}

Parents LRA 5166, G.Cot.100, G.Cot.10 ; LH 900 , LH-900 ; G(B) 20, G.Cot.100 recorded significant positive g.c.a. effects in all the three methods, respectively.

The estimates of s.c.a. effects of hybrids revealed that LRK 516 x G.Cot.10 of conventional method, cross, PH $93 \times$ G.Cot.10 and LRK 516 x G.Cot.10 of GMS based hybrids and
PH 93 x DHY 286-1 and G.Cot.100 x G.Cot.10 of CMS based hybrids showed significant and positive s.c.a. effects.

\section{Fibre strength (g/tex)}

The perusal of estimates of general combining ability effects of parents showed that G.Cot.10; LRK 516; and LH 900 and DHY 286-1 of conventional, GMS and CMS method parents, respectively recorded positive and significant g.c.a. effects. The perusal of s.c.a. effects revealed that LRA $5166 \times$ DHY 286-1 and LRK 516 x G.Cot.10 of conventional hybrids, LRA 5166 x G.Cot.10 of GMS based cross and 76 IH $20 \times$ G.Cot.10, PH 93 x DHY 286-1, LRA 5166 x DHY 286-1, LRK 516 x DHY 286-1 and G(B) 20 x G.Cot.10 of CMS method hybrids showed significant positive s.c.a. effects.

\section{Discussion}

The concept of combining ability is considered to be a land mark in the development of efficient and effective breeding methodology in different crop plants. Analysis of combining ability provides guidelines for an early assessment of the relative breeding worth of the parent material. Utilizing this technique the breeder can choose the best general combining parents as well as specific cross combinations for further exploitation. The parental material may be used to develop hybrids or build up the favourable fixable genes depending upon the nature of gene action.

Analysis of variance for combining ability for data revealed that both additive as well as non-additive variances were important in the inheritance of various traits as evident from the significance of females, males and females $\mathrm{x}$ male interaction for most of the characters.

The estimates of components of variances (g.c.a. and s.c.a.) and their ratios ( $\sigma^{2}$ g.c.a./ $\sigma^{2}$ s.c.a.) indicated that both additive and non-additive type of variances were important in the inheritance of the characters. However, the s.c.a. variances were greater than g.c.a. variances for all the characters except days to 50 per cent flowering, seeds per boll and seed index, indicating the non-additive gene effects, thus, it emphasizes the use of heterosis breeding approach to exploit available vigour in this crop. On the other hand, additive type of gene effect played important role in the inheritance of days to 50 per cent flowering, seeds per boll, seed index and seed cotton yield per plant, which suggests the directional selection for isolating better homozygous lines from the segregating populations for these traits.

In view of this situation breeding procedure which exploits both additive as well as non-additive genetic effects need to be adopted for making yield improvement in such materials. Under such circumstances, recurrent selection procedure seems to be the most appropriate breeding method.

Mean squares due to females $\mathrm{x}$ locations and males $\mathrm{x}$ locations were found to be not-significant for most of the traits except days to 50 per cent flowering, and fibre length, which indicated that g.c.a. variances of female and males were not influenced by the environments. The s.c.a. variances were more sensitive to environmental fluctuations as evident by the significance of mean squares due to females $\mathrm{x}$ males $\mathrm{x}$ locations interaction for all the characters except days to 50 per cent flowering, 2.5 per cent span length and fibre strength. Based on estimates of general combining ability effects on pooled basis for various characters, the parents were classified as good, average and poor combiners (Table 3). It was observed that among the parents, G(B) 20 was found to be good general combiner for all the traits except plant height and ginning percentage and average combiner for days to 50 
per cent flowering, seed index and fibre strength, whereas, LRK-516 was found to be good general combiner for all the traits except ginning percentage and average combiner for 2.5 per cent span length and number of bolls per plant. Therefore these two parents were noted as good source of favourable genes for increasing seed cotton yield through various yield contributing characters. LRA-5166 is found to be average general combiner for all the traits except boll weight, number of seeds per boll and seed index.

The parents, PH-93, LRK-516 and G.Cot.10 were good general combiners for days to 50 per cent flowering, whereas for plant height, LH-900, LRA-5166, LRK-516 and DHY286-1 were good general combiners. For number of monopodia per plant $G(B) 20$ was good general combiner, whereas LRK-516, G(B) 20 and G.Cot.100 were general combiners for number of sympodia per plant. For the character number of bolls per plant LRA-5166, G(B)-20 and DHY-286-1 were good general combiners, whereas for boll weight LH-900, LRK-516, G(B)-20, G.Cot.100 and G.Cot.10 were good general combiners. The parents G(B)-20, G.Cot.100 and DHY-286-1 were good general combiners for number of seeds per boll, whereas LRK-516 and G(B)-20 were good general combiners for seed index, while PH-93 was good general combiner for ginning percentage. For seed cotton yield per plant, parents LRK-516, G(B) 20 and DHY286-1 were good general combiners. The parents LH-900, G(B) 20 and G.Cot.100 were good general combiners for 2.5per cent span length, whereas LH-900 was good general combiner for fibre strength.

The close relationship between parent per se performance and their general combining ability is important in the choice of parents for hybrid breeding programme (Gupta and Singh, 1974; and Singh et al., 1988) ${ }^{[2,12]}$. In the present study, the parents with high mean values had high s.c.a. effects for majority of characters (Table 3). However, this was not true for all the characters in all the cases, suggesting that inter allelic interaction were important for these characters. Similar results have been reported by Verma et al., (1991) ${ }^{[14]}$, Jagtap and Kolhe (1993) ${ }^{[4]}$, Vadodaria and Patel (1995) ${ }^{[13]}$ and Patel et al., (1997) [9].

A summarised account of the best parent, best general combiner, best $\mathrm{F}_{1}$ per se, most heterotic crosses and best specific combination (Table 3) revealed that the best performing parent may not always be a best general combiner. Further, the best general combiners may not always produce best specific combinations for all the characters (Patel et al. 1996 and Modi et al. 1999 a, b) ${ }^{[6,7]}$. However in some of the cases, high s.c.a. effects of crosses coinside with high g.c.a. effects of their parents. The parent G(B) 20 had high per se performance coupled with good general combining ability for seed cotton yield. The cross G(B) 20 x G.Cot.10 manifested high heterosis coupled with high s.c.a. effects for seed cotton yield. This may be attributed to inclusion of one of the good combining parents for their seed cotton yield or yield components. Such combinations may give desirable transgressive segregants and these could be utilized for the improvement of genotypes, if additive genetic effect is present with complementary epistatic effect. Pathak and Kumar (1975) ${ }^{[11]}$ also reported close relationship between g.c.a. effects of parents and their s.c.a. effects in hirsutum crosses.

The crosses exhibiting high order positive or negative specific combining ability effects involved either good $\mathrm{x}$ good, good $\mathrm{x}$ average, good $\mathrm{x}$ poor, average $\mathrm{x}$ average, average $\mathrm{x}$ poor or poor $\mathrm{x}$ poor combining parents. The good general combining parents when crossed do not always produce high s.c.a. effects. Similar results have been reported by Verma et al., (1991) ${ }^{[14]}$, Singh et al. (1988) ${ }^{[12]}$ and Patel et al. (1997) ${ }^{[9]}$. The negative effects in crosses between good $\mathrm{x}$ good and good $\mathrm{x}$ average combiners could be attributed to the lack of co-adaptation between favourable allels of the parents involved. Whereas the positive effects in crosses between poor $\mathrm{x}$ poor, average $\mathrm{x}$ average or average $\mathrm{x}$ poor combiners could be attributed to better complementation between favourable allels of the parents involved (Patel and Mehta, 1985 and Patel and Pethani, 1995) ${ }^{[8]}$.

A comparison of the crosses selected on the basis of s.c.a. effects with their mean performance in their environments revealed some important features viz., (1) the relative ranking of the various crosses on the basis of s.c.a. effects was different in different environments (2) the ranking on the basis of s.c.a effects was not always reflected by the ranking based on per se performance (Table 3) and (3) crosses showing high mean performance had not always shown high s.c.a. effect. There was no consistant association between per se performance of parents and their s.c.a. effects. Although, high s.c.a. effects denote high heterotic responce, this may be due to poor performance of the parents in comparison with their hybrids. Even with the same amount of heterotic effects, the s.c.a. effects may be lower where the mean performance of the parents is higher. This suggests that estimates of s.c.a. effects may not always lead to a correct choice of hybrid combination. These estimates may also be biased because of non-fulfilment of any of the assumptions involved in the models. Hence, the choice of best cross combinations on the basis of per se performance could be more realistic and useful. Similar findings were reported by Pathak and Kumar (1975) ${ }^{[11]}$, Singh et al., (1988) ${ }^{[12]}$, Gururaja and Basu (1992) ${ }^{[3]}$ and Patel et al., (1997) ${ }^{[9]}$.

In cotton, the variety/hybrid with short duration and dwarf type is desirable. Hence the parent LRK-516 with high negative g.c.a. effects for plant height and days to 50 per cent flowering seems to be useful for breeding for short stature and early maturing variety/hybrid in hirsutum cotton.

Increase in yield, accompained by a good standard of quality characters viz., 2.5 per cent span length, ginning percentage and fibre strength is always desirable. In the present investigation, the parent $G(B) 20$ could be spotted out as a good general combiner for yield and yield contributing characters and average combiner for seed index and fibre strength. Thus by using this parent in breeding programme, there is a good scope for increasing yield without loss in quality characters.

The general combining ability effects and specific combining ability effects of conventional, GMS and CMS parents and their resultant crosses for seed cotton yield per plant (Table 3) stated that the estimates of gca effects were higher in magnitude in conventional system followed by GMS and CMS system and the sca effects were higher in magnitude in conventional system as compared to GMS and CMS system. But certain parents and crosses of GMS and CMS system showed significant gca and sca effects which indicated the possibility of fruitful utilization of GMS and CMS systems for development of commercial hybrids. Silva et al., 1983; Somoro et al., 1989; Patel et al., 1997 [9]; Anonymous, 1998; Shekhar et al., 1999 also reported the similar results.

The s.c.a. effects represent dominance and epistatic effects and can be related with heterosis (Falconer, 1960) ${ }^{[1]}$. From the observations made in the present study the following points emerged. 
1. The relation between per se performance and the s.c.a. effects of hybrids for majority of characters indicated that s.c.a. effects of a cross can reasonably be predicted from their per se performance. However, the inspection of s.c.a. effects and mean performance of individual crosses indicated that the crosses having high s.c.a. effects did not always possess high mean values (Table 3). High s.c.a effects denote, undoobtedly, high heterotic response, but this may also be due to the very poor performance of parents in comparison with their hybrids. Indeed, even with the same amount of heterotic effect, the s.c.a. effects may be lower when the mean performance of the parents is higher. This showed that estimates of s.c.a. effects may not always lead to the correct choice of hybrid combinations. Although the relative amount of g.c.a. and s.c.a. effects play a vital role in planning the most appropriate breeding programme, this objective could be fulfilled by the analysis of variance for combining ability, itself. It is therefore, advisable to give more emphasis to the per se performance rather than the estimates of s.c.a. effects.

2. The crosses identified having high s.c.a. effect for seed cotton yield also had high s.c.a. effect for boll number. The components like sympodia per plant, boll weight, seed index showed lack of association with seed cotton yield, thereby limiting the utility of these characters in identifying superior cross combination.

3. The crosses exhibiting high s.c.a. effects did not always involve the parents having high g.c.a. effects (Table 3). Any parental combination of either good x good, good $\mathrm{x}$ poor and poor $\mathrm{x}$ poor may result in to high s.c.a. effects (Table 3).

4. The crosses exhibiting high s.c.a. effects were not always the result of good $x$ good combination with respect to mean performance. Hence choice of the parents on the basis of combining ability together with per se performance is advisable.

5. The general combining ability effects and specific combining ability effects of conventional, GMS and CMS parents and their resultant crosses for seed cotton yield per plant stated that the estimates of gca effects were higher in magnitude in conventional system followed by GMS and CMS system and the sca effects were higher in magnitude in conventional system as compared to GMS and CMS system. But certain parents and crosses of GMS and CMS system showed significant gca and sca effects which indicated the possibility of fruitful utilization of GMS and CMS systems for development of commercial hybrids.

Table 1a: Analysis of variance (mean squares) of combining ability

\begin{tabular}{|c|c|c|c|c|c|c|c|c|c|c|c|c|c|}
\hline \multirow{2}{*}{$\begin{array}{l}\text { Sources of } \\
\text { variance }\end{array}$} & \multirow{2}{*}{ D.F } & \multicolumn{3}{|c|}{ days to 50 per cent flowering } & \multicolumn{3}{|c|}{ plant height (cm) } & \multicolumn{3}{|c|}{$\begin{array}{c}\text { No. of monoposia per } \\
\text { plant }\end{array}$} & \multicolumn{3}{|c|}{ No. of sympodia per plant } \\
\hline & & CON & GMS & CMS & $\mathrm{CON}$ & GMS & CMS & CON & GMS & CMS & CON & GMS & CMS \\
\hline & & Pooled & Pooled & Pooled & Pooled & Pooled & Pooled & Pooled & Pooled & Pooled & Pooled & Pooled & Pooled \\
\hline Locations & 2 & $394.67 * *$ & $148.80 * *$ & $220.49 * *$ & $553.27 * *$ & $1677.61 * *$ & $1077.22 * *$ & $0.75^{*}$ & $1.46^{* *}$ & $0.54 *$ & $125.78 * *$ & $188.99 * *$ & $421.19 * *$ \\
\hline Females & 6 & $711.25 * *$ & $497.27 *$ & $556.15 * *$ & $9659.56 * *$ & $10393.26 * *$ & $8050.72 * *$ & $3.26 * *$ & $1.78 * *$ & 2.84 & $158.48 * *$ & $120.44 * *$ & $54.38 * *$ \\
\hline Males & 1 & $25.33 .51 * *$ & $1730.84 * *$ & $2000.10 * *$ & 1017.67 & $1339.76 * *$ & 25.82 & 0.01 & $2.62 * *$ & 0.36 & 26.50 & $35.23 * *$ & $91.24 * *$ \\
\hline Females x Male & 6 & $63.18 * *$ & $66.18 * *$ & $47.79 * *$ & $643.44 *$ & 74.33 & 630.10 & 4.70 & 2.20 & $4.82 *$ & 47.57 & 35.76 & 32.88 \\
\hline Females x Loc. & 12 & $30.28 * *$ & $31.10 * *$ & $43.93 * *$ & 339.07 & 21.43 & $706.22 *$ & 2.70 & 2.68 & 1.48 & 29.10 & 58.17 & 48.18 \\
\hline Males x Loc. & 2 & 6.59 & 0.69 & 06 & 84.16 & 0.49 & 2.70 & 33 & 3.34 & 2.70 & 17.76 & 24.80 & 53.66 \\
\hline Fm x M x Loc. & 12 & 16.89 & 17 & & $180.76^{*}$ & $296.08 * *$ & $256.26 * *$ & $2.38 * *$ & $2.30 * *$ & $1.10 * *$ & $96.75 * *$ & $56.84 * *$ & $83.41 * *$ \\
\hline Pooled error & $78 @$ & 13.31 & 11.52 & & 77.16 & 56.29 & 65.14 & 0.20 & 0.21 & 0.16 & 7.50 & 101.48 & 12.01 \\
\hline$\sigma^{2}$ g.c.a. & & 38.33 & 25.80 & 30.26 & 115.16 & 115.89 & 81.72 & 0.05 & 0.01 & 0.10 & 2.91 & 1.41 & 1.78 \\
\hline$\sigma^{2}$ s.c.a. & & 15.43 & 16.00 & 9.98 & 154.23 & 129.08 & 124.61 & 0.77 & 0.03 & 0.31 & 16.39 & 7.03 & 16.85 \\
\hline$\sigma^{2}$ g.c.a/ $\sigma^{2}$ s.c.a. & & 2.48 & 1.61 & 3.03 & 0.74 & 0.77 & 0.65 & 0.07 & 0.56 & 0.33 & 0.17 & 0.20 & 0.10 \\
\hline
\end{tabular}

Table 1b: Analysis of variance (mean squares) of combining ability

\begin{tabular}{|c|c|c|c|c|c|c|c|c|c|c|c|c|c|}
\hline \multirow{2}{*}{ Sources of variance } & \multirow{2}{*}{ D.F } & \multicolumn{3}{|c|}{ number of bolls per plant } & \multicolumn{3}{|c|}{ boll weight (g) } & \multicolumn{3}{|c|}{ number of seeds per boll } & \multicolumn{2}{|c|}{ seed index $(g)$} & \multirow[b]{2}{*}{ CMS } \\
\hline & & CON & GMS & CMS & CON & GMS & CMS & CON & GMS & CMS & CON & GMS & \\
\hline & & Pooled & Pooled & Pooled & Pooled & Pooled & Pooled & Pooled & Pooled & Pooled & Pooled & Pooled & Pooled \\
\hline Locations & 2 & $894.40 * *$ & $77.47 * *$ & $531.72 * *$ & $14.68^{* *}$ & 11.89 & 8.96 & 18.45 & 20.86 & 14.06 & $17.57 * *$ & $9.57 * *$ & 0.88 \\
\hline Females & 6 & $186.84 * *$ & $226.26 * *$ & $271.96 * *$ & $2.62 * *$ & $1.22 * *$ & $21.20 * *$ & $118.98 * *$ & $141.92 * *$ & $196.08 * *$ & $16.12 * *$ & $6.40 * *$ & $13.42 * *$ \\
\hline Males & 1 & $103.92 * *$ & $243.56^{* *}$ & $361.93 * *$ & $0.90 * *$ & 0.13 & 0.06 & $305.50 * *$ & $48.53 *$ & $207.71 * *$ & 0.50 & 1.83 & $8.74 * *$ \\
\hline Females x Male & 6 & 86.88 & 155.47 & 238.53 & 0.59 & 1.05 & 0.76 & & 62.75 & 22.17 & 4.26 & 7.16 & 4.01 \\
\hline Females x Loc. & 12 & 167.07 & 152.40 & 100.92 & 0.64 & 0.57 & 0.56 & 35.09 & 49.62 & $55.07 * *$ & 7.19 & 4.10 & 3.96 \\
\hline Males x Loc. & 2 & $216.07 *$ & $335.95 *$ & 138.12 & $3.34 *$ & $4.85 * *$ & 0.80 & 45.62 & 93.74 & 23.66 & 1.95 & 7.80 & 2.73 \\
\hline Fm x M x Loc. & 12 & $67.70 * *$ & $82.71 * *$ & $115.65^{* *}$ & $0.86^{* *}$ & $0.50 * *$ & $0.42 * *$ & $42.12 * *$ & $61.48 * *$ & $19.52 *$ & 4.25 & $5.00 * *$ & $3.96^{* *}$ \\
\hline Pooled error & 78@ & 7.54 & 9.69 & 12.48 & 0.03 & 0.04 & 0.04 & 6.65 & 6.91 & 8.90 & 1.21 & 1.12 & 1.12 \\
\hline$\sigma^{2}$ g.c.a. & & 1.61 & 2.02 & 1.84 & 0.01 & 0.06 & 0.01 & 4.90 & 0.54 & 3.92 & 0.09 & 0.09 & 0.18 \\
\hline$\sigma^{2}$ s.c.a. & & 6.39 & 24.25 & 40.96 & 0.09 & 0.18 & 0.11 & 8.96 & 0.42 & 0.87 & 0.06 & 0.72 & 0.02 \\
\hline$\sigma^{2}$ g.c.a/ $\sigma^{2}$ s.c.a. & & 0.29 & 0.08 & 0.04 & 0.01 & 0.35 & 0.01 & 0.54 & 1.30 & 4.51 & 1.53 & 0.13 & 9.45 \\
\hline
\end{tabular}


Table 1c: Analysis of variance (mean squares) of combining ability

\begin{tabular}{|c|c|c|c|c|c|c|c|c|c|c|c|c|c|}
\hline \multirow{2}{*}{ Sources of variance } & \multirow{2}{*}{ D.F } & \multicolumn{3}{|c|}{ ginning percentage (\%) } & \multicolumn{3}{|c|}{ seed cotton yield per plant $(\mathrm{g})$} & \multicolumn{3}{|c|}{2.5 per cent span length $(\mathrm{mm})$} & \multicolumn{3}{|c|}{ fibre strength (g/tex) } \\
\hline & & CON & GMS & CMS & CON & GMS & CMS & CON & GMS & CMS & CON & GMS & CMS \\
\hline & & Pooled & Pooled & Pooled & Pooled & & & Pooled & & & Pooled & Poo & \\
\hline & 2 & 48.1 & 17.6 & $62.89 * *$ & 4989 & 24740 . & 35220 & 88. & 54 & ** & $31.80 * *$ & 90 & 0 \\
\hline & 6 & 171.94 & $83.49 * *$ & $102.84 * *$ & $4759.54 * *$ & 39. & & & & & 4 & & \\
\hline & 1 & 1.77 & & $25.18 * *$ & 64.23 & 269 & & & & & & 47 & 10.49 \\
\hline & 6 & $56.24 * *$ & & & 975 & & & & & & & .31 & $13.82 * *$ \\
\hline & 12 & $49.70 * *$ & & & 10 & & & 15. & & & & & 1.18 \\
\hline & 2 & $40.56^{* *}$ & 44.08 & & & & & 9.8 & & & & 9 & .90 \\
\hline & 12 & 10.36 & $21.85^{* *}$ & $33.99 * *$ & 914. & & 072 & & & & & & .67 \\
\hline Poole & $78 @$ & 5.72 & & & & & & 2.9 & & & 4 & 39 & 2.74 \\
\hline & & 010 & & & 3 & & & & 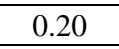 & & 0. & 0.08 & 0.09 \\
\hline$\sigma^{2} s$. & & 15.29 & & & 20.20 & & & & & & & 1.61 & 4.38 \\
\hline$\sigma^{2}$ g.c.a/ $\sigma^{2}$ s.c.a. & & 6.67 & 0.04 & 0.12 & 1.85 & 2.00 & 2.56 & 0.21 & 0.14 & 0.01 & 0.49 & 0.05 & 0.02 \\
\hline
\end{tabular}

Table 2a: Estimates of general combining ability (gca) effects and specific combining ability (sca) effects

\begin{tabular}{|c|c|c|c|c|c|c|c|c|c|c|c|c|}
\hline \multirow[t]{2}{*}{ Parents/crosses } & \multicolumn{3}{|c|}{ days to $50 \%$ flowering } & \multicolumn{2}{|c|}{ plant height $(\mathrm{cm})$} & \multirow{2}{*}{\begin{tabular}{|c|}
$\begin{array}{c}\text { No. of } \\
\text { monopodia } \\
\text { per plant }\end{array}$ \\
CMS \\
\end{tabular}} & \multirow[b]{2}{*}{ CON } & \multirow[b]{2}{*}{ GMS } & \multirow[b]{2}{*}{ CMS } & \multicolumn{3}{|c|}{ No. of sympodia per plant } \\
\hline & CON & GMS & CMS & CON & GMS & & & & & CON & GMS & CMS \\
\hline & Pooled & Pooled & Pooled & Pooled & Pooled & Pooled & Pooled & Pooled & Pooled & Pooled & Pooled & Pooled \\
\hline \multicolumn{13}{|l|}{ Females } \\
\hline $76 \mathrm{IH} 20$ & 61 & 31 & -0.15 & $9.52 * *$ & $23.93 * *$ & $22.62 * *$ & $-0.36 * *$ & $23 * *$ & $-0.18 *$ & $-3.66 * *$ & -0.58 & $-1.65 * *$ \\
\hline LH 900 & $1.83 * *$ & & $1.24 *$ & $-20.99 * *$ & $-18.33 * *$ & $-23.15 * *$ & $-0.41 * *$ & $-0.40 * *$ & $-0.16 *$ & $-3.98 * *$ & $-1.17 *$ & 0.51 \\
\hline PH 93 & $-3.73 * *$ & $3.81 * *$ & $-4.60 * *$ & $16.53^{* *}$ & $18.23 * *$ & $16.43^{* *}$ & $-0.45 * *$ & 0.00 & $-0.57 * *$ & 0.34 & $-4.37 * *$ & $-2.01 * *$ \\
\hline LRA 5166 & -0.50 & $-2.09 * *$ & -0.37 & $-19.07 * *$ & $-19.32 * *$ & $-8.28 * *$ & 0.14 & $-0.17 *$ & 0.07 & -0.26 & -0.91 & 0.61 \\
\hline LRK 516 & $9.22 * *$ & $-5.48 * *$ & $-7.04 * *$ & $-30.76 * *$ & $-36.44 * *$ & $-31.57 * *$ & $0.23 * *$ & -0.01 & $-0.17 *$ & 0.84 & $3.45^{* *}$ & $2.18 * *$ \\
\hline $\mathrm{G}(\mathrm{B}) 20$ & -0.50 & -0.20 & 0.29 & $9.32 * *$ & $13.48 * *$ & $9.27 * *$ & $0.70 * *$ & $0.56^{* *}$ & $0.62 * *$ & $3.33 * *$ & $1.50^{* *}$ & $2.23 * *$ \\
\hline G.Cot. 100 & $11.56^{* *}$ & $10.75 * *$ & $10.63 * *$ & $15.45^{* *}$ & $17.94 * *$ & $14.67 * *$ & 0.15 & $-0.21^{*}$ & $0.39 * *$ & $3.40 * *$ & $2.09^{* *}$ & -0.75 \\
\hline $\mathrm{SE}\left(\mathrm{g}_{\mathrm{i}}\right) \pm$ & 0.62 & 0.58 & 0.54 & 1.50 & 1.28 & 1.37 & S & 0.08 & 0.07 & 0.47 & 0.55 & 0.59 \\
\hline \multicolumn{13}{|l|}{ Males } \\
\hline s.Cot. 10 & $48 * *$ & $-3.71 * *$ & $-3.98 * *$ & $2.84 * *$ & $1.64 * *$ & 0.44 & 0.01 & $0.14 \cdots$ & 0.05 & -0.46 & -0.53 & $-0.85 * *$ \\
\hline DHY 286-1 & $4.48^{* *}$ & $3.71 * *$ & $3.98 * *$ & $-2.84 * *$ & $-1.64 * *$ & -0.44 & -0.01 & $-0.14 * *$ & -0.05 & 0.46 & 0.53 & $0.85 * *$ \\
\hline $\operatorname{SE}\left(g_{j}\right) \pm$ & 0.25 & 0.24 & 0.22 & 0.61 & 0.52 & 0.56 & 0.03 & 0.03 & 0.03 & 19 & 0.23 & 0.84 \\
\hline \multicolumn{13}{|l|}{ Crosses } \\
\hline 76 IH 20 x G.C & $26^{*}$ & 07 & $1.15^{*}$ & -0.69 & $-2.60 *$ & $3.13 *$ & $0.46^{* *}$ & 0.07 & $0.68 * *$ & $-1.43 * *$ & -0.68 & 0.73 \\
\hline 76 IH 20 x DHY 286-1 & $-1.26^{*}$ & 0.07 & -1.15 & 0.69 & $2.60 *$ & $-3.13 *$ & $-0.46^{* *}$ & -0.07 & $-0.68 * *$ & $1.43 * *$ & 0.68 & -0.73 \\
\hline LH 900 x G.Cot.10 & $2.93 * *$ & $4.04 * *$ & $2.76^{* *}$ & -2.77 & $-5.77 * *$ & $-3.52 *$ & $-0.58 * *$ & $0.20 *$ & -0.08 & -0.09 & $-1.16^{* *}$ & -0.57 \\
\hline LH 90 & $-2.93 * *$ & $-4.04 * *$ & -2.76 & 2.77 & $5.77 * *$ & $3.52 *$ & $0.58^{*}$ & $-0.20 *$ & 0.08 & 0.09 & $1.16^{* *}$ & 0.57 \\
\hline PH 93 x G.Cot.10 & -0.57 & -0.90 & -0.52 & -0.73 & -2.37 & -2.76 & $0.64 * *$ & $0.36^{* *}$ & $0.60 * *$ & $-1.12 * *$ & $2.13^{* *}$ & $-1.72 * *$ \\
\hline PH 93 x DHY 286-1 & 0.57 & 0.90 & 0.52 & 0.73 & 2.37 & 2.76 & $-0.64 * *$ & $-0.36 * *$ & $-0.60 * *$ & $1.12 * *$ & $-2.13 * *$ & $1.72 * *$ \\
\hline LRA 5166 x G.Cot. 10 & -0.63 & -0.52 & -1.02 & $-6.79 * *$ & $-6.16^{* *}$ & $-7.99 * *$ & $0.20 *$ & $-0.24 * *$ & $-0.49 * *$ & $2.99 * *$ & 0.96 & 0.55 \\
\hline LRA 5166 x DHY $286-1$ & 0.63 & & 1.02 & $6.79 * *$ & $6.16^{* *}$ & $7.99 * *$ & $-0.20^{*}$ & $0.24 * *$ & $0.49 * *$ & $-2.99 * *$ & -0.96 & -0.55 \\
\hline LRK 516 x G.Cot.10 & $-2.79 * *$ & $-1.35^{*}$ & -0.40 & $-4.18 * *$ & 2.05 & -1.16 & $-0.64 * *$ & $-0.68 * *$ & $0.73 * *$ & $-1.46 * *$ & $-1.92 * *$ & $-1.22 * *$ \\
\hline LRK 516 x DHY 286-1 & $2.79 * *$ & $1.35^{*}$ & 0.40 & $4.18 * *$ & -2.05 & 1.16 & $0.64 * *$ & $0.68 * *$ & $-0.73^{* * *}$ & $1.46^{* *}$ & $1.92 * *$ & $1.22 * *$ \\
\hline G(B) 20 x G.Cot. 10 & -1.18 & $-1.63 * *$ & $-2.29 * *$ & $11.27 * *$ & $12.41 * *$ & $10.59 * *$ & $0.24 * *$ & $0.18 *$ & -0.05 & $1.20 * *$ & 0.95 & -0.09 \\
\hline G(B) 20 x DHY 286-1 & 1.18 & $1.63 * *$ & $2.29 * *$ & $-11.27 * *$ & $-12.41 * *$ & $-10.59 * *$ & $-0.24 * *$ & $-0.18^{*}$ & 0.05 & $-1.20 * *$ & -0.95 & 0.09 \\
\hline G.Cot. 100 x G.Cot. 10 & & & & $3.89 *$ & 2.45 & 1.70 & $-0.32 * *$ & 0.12 & 0.07 & -0.10 & -0.28 & $-2.32 * *$ \\
\hline G.Cot.100 x DHY 286-1 & -0.98 & -0.43 & -0.37 & $-3.89 *$ & -2.45 & -1.70 & $0.32 * *$ & -0.12 & -0.07 & 0.10 & 0.28 & $-2.32 * *$ \\
\hline $\operatorname{SE}\left(g_{i j}\right) \pm$ & 0.62 & 0.58 & 0.54 & 1.50 & 1.28 & 1.37 & 0.08 & 0.08 & 0.07 & 0.47 & 0.55 & 0.59 \\
\hline
\end{tabular}

Table 2b: Estimates of general combining ability (gca) effects and specific combining ability (sca) effects

\begin{tabular}{|c|c|c|c|c|c|c|c|c|c|c|c|c|}
\hline \multirow{2}{*}{ Parents/crosses } & \multicolumn{3}{|c|}{ No. of bolls per plant } & \multicolumn{3}{|c|}{ boll weight (g) } & \multicolumn{3}{|c|}{ seeds per boll } & \multicolumn{3}{|c|}{ seed index $(\mathrm{g})$} \\
\hline & CON & GMS & CMS & CON & GMS & CMS & CON & GMS & CMS & CON & GMS & CMS \\
\hline & Pooled & Pooled & Pooled & Pooled & Pooled & Pooled & Pooled & Pooled & Pooled & Pooled & Pooled & Pooled \\
\hline \multicolumn{13}{|l|}{ Females } \\
\hline $76 \mathrm{IH} 20$ & -0.67 & $2.30 * *$ & $-2.44 * *$ & $-0.23 * *$ & $-0.27 * *$ & $-0.39 * *$ & -0.54 & -0.75 & $-2.05 * *$ & 0.15 & $-0.39 *$ & $-1.00 * *$ \\
\hline LH 900 & $-2.89 * *$ & $-6.95 * *$ & $-7.22 * *$ & $0.20 * *$ & $0.19 * *$ & $0.11 * *$ & 0.13 & $-2.10 * *$ & $-2.63 * *$ & $-0.57 * *$ & 0.05 & $-0.47 *$ \\
\hline PH 93 & 0.46 & -0.47 & $3.66 * *$ & $-0.53 * *$ & $-0.36 * *$ & $-0.48 * *$ & $-5.36 * *$ & $-3.16^{* *}$ & $-2.47 * *$ & $-1.12 * *$ & $-0.55 * *$ & $-0.76^{* *}$ \\
\hline LRA 5166 & $5.96 * *$ & $1.09 *$ & 0.30 & $-0.41 * *$ & $-0.15 * *$ & $-0.13 * *$ & $1.58 * *$ & $-2.34 * *$ & $-1.95 * *$ & $-1.05 * *$ & $-0.69 * *$ & -0.15 \\
\hline LRK 516 & $-3.18 * *$ & -0.79 & -0.43 & $0.30 * *$ & $0.31 * *$ & $0.14 * *$ & 0.76 & $3.00 * *$ & -0.04 & $1.13 * *$ & $0.81 * *$ & 0.07 \\
\hline $\mathrm{G}(\mathrm{B}) 20$ & $2.11 * *$ & $4.43 * *$ & $3.00 * *$ & $0.43 * *$ & $0.22 * *$ & $0.36 * *$ & $2.62 * *$ & $4.00 * *$ & $5.53 * *$ & 0.34 & 0.03 & $1.12 * *$ \\
\hline G.Cot. 100 & -1.78 & 0.33 & $3.14 * *$ & $0.23 * *$ & 0.06 & $0.39 * *$ & 0.83 & $1.35 * *$ & $3.62 * *$ & $1.13^{* *}$ & $0.74 * *$ & $1.18^{* *}$ \\
\hline $\mathrm{SE}\left(\mathrm{g}_{\mathrm{i}}\right) \pm$ & 0.47 & 0.53 & 0.60 & 0.03 & 0.03 & 0.04 & 0.44 & 0.45 & 0.51 & 0.19 & 0.18 & 0.18 \\
\hline \multicolumn{13}{|l|}{ Males } \\
\hline G.Cot. 10 & $-0.91 * *$ & $-1.39 * *$ & $-1.70 * *$ & $0.08^{* *}$ & $0.03 * *$ & -0.02 & $-1.56^{* *}$ & $-0.62 * *$ & $-1.28 * *$ & -0.06 & -0.12 & $-0.26 * *$ \\
\hline
\end{tabular}




\begin{tabular}{|c|c|c|c|c|c|c|c|c|c|c|c|c|}
\hline DHY 286-1 & $0.91 * *$ & $1.39 * *$ & $1.70 * *$ & $-0.08 * *$ & $-0.03^{* *}$ & 0.02 & $1.56^{* *}$ & $0.62 * *$ & $1.28 * *$ & 0.06 & 0.12 & $0.26 * *$ \\
\hline $\operatorname{SE}\left(g_{j}\right) \pm$ & 0.19 & 0.27 & 0.25 & 0.01 & 0.01 & 0.01 & 0.18 & 0.18 & 0.21 & 0.08 & 0.07 & 0.07 \\
\hline \multicolumn{13}{|l|}{ Crosses } \\
\hline 76 IH 20 x G.C & .21 & 1.03 & $-3.50 * *$ & $-0.24 * *$ & $-0.26^{* *}$ & 0.02 & -0.03 & $2.32 * *$ & 0.00 & $0.52 *$ & $-0.76 * *$ & $-0.41 *$ \\
\hline $76 \mathrm{IH} 20 \times \mathrm{I}$ & 0.27 & -1.03 & $3.50 * *$ & $0.24 * *$ & $0.26^{* *}$ & -0.02 & 0.03 & $2.32 * *$ & 0.00 & $-0.52^{*}$ & $0.76^{* *}$ & $0.41 *$ \\
\hline LH $900 x$ & $2.06 * *$ & $5.44 * *$ & 0.52 & $-0.23 * *$ & $-0.20^{* *}$ & $-0.16^{* *}$ & -0.59 & $-1.53^{* *}$ & -0.89 & $-0.86^{* *}$ & -0.12 & $-0.54 * *$ \\
\hline LH 900 x DHY 286-1 & $-2.06 * *$ & $5.44 * *$ & -0.52 & $0.23 * *$ & $0.20 * *$ & $0.16^{* *}$ & 0.59 & $1.53 * *$ & 0.89 & $0.86^{* *}$ & 0.12 & $0.54 * *$ \\
\hline PH 93 x G.Cot.10 & $1.31 * *$ & $1.82 * *$ & $-1.65 * *$ & $0.17 * *$ & 0.04 & $0.09 *$ & 0.55 & $2.20 * *$ & -0.46 & -0.11 & $-0.62 * *$ & $0.42 *$ \\
\hline PH 93 x DHY 286-1 & $-1.31 * *$ & $-1.82 * *$ & $1.65 * *$ & $-0.17 * *$ & -0.04 & $-0.09 *$ & -0.55 & $2.20 * *$ & 0.46 & 0.11 & $0.62 * *$ & $-0.42^{*}$ \\
\hline LRA 5166 & $-1.68 * *$ & $2.22 * *$ & -0.92 & $0.13 * *$ & $0.19 * *$ & $0.20 * *$ & $1.06^{*}$ & -0.16 & $1.10^{*}$ & -0.31 & $1.09 * *$ & $0.81 * *$ \\
\hline LRA 5166 x DHY 286-1 & $1.68 * *$ & $-2.22 * *$ & 0.92 & $-0.13 * *$ & $-0.19 * *$ & $-0.20 * *$ & $-1.06^{*}$ & 0.16 & -1.10 & -0.31 & $-1.09 * *$ & $-0.81 * *$ \\
\hline LRK 516 x G.Cot.10 & $-4.06 * *$ & $-1.52 * *$ & 0.20 & 0.02 & $-0.18^{* *}$ & $-0.22 * *$ & $-1.23 * *$ & -0.32 & -0.64 & $0.42 *$ & -0.08 & -0.02 \\
\hline LRK 516 x DHY 286-1 & $4.06 * *$ & $1.52 * *$ & -0.20 & -0.02 & $0.18 * *$ & $0.22 * *$ & $1.23 * *$ & 0.32 & 0.64 & $-0.42^{*}$ & 0.08 & 0.02 \\
\hline G(B) 20 x G.Cot.10 & $1.11 *$ & $3.03 * *$ & $7.63^{* * *}$ & -0.04 & 0.01 & $-0.22 * *$ & $1.06^{*}$ & -0.67 & $-1.03 *$ & 0.06 & $0.47 *$ & -0.04 \\
\hline $\mathrm{G}(\mathrm{B}) 20 \mathrm{x}$ & $-1.11^{*}$ & $-3.03 * *$ & $-7.63 * *$ & 0.04 & -0.01 & $0.22 * *$ & $-1.06^{*}$ & 0.67 & $1.03 *$ & -0.06 & $-0.47 *$ & 0.04 \\
\hline G.Cot.100 x G.Cot.10 & $1.53 *$ & $-1.15^{*}$ & $-2.27 * *$ & $0.20 * *$ & $0.42 * *$ & $0.28 * *$ & -0.83 & $2.79 * *$ & $1.93 * *$ & -0.35 & 0.03 & -0.22 \\
\hline G.Cot.100 x DHY 286-1 & $-1.53^{*}$ & $1.15^{*}$ & $2.27 * *$ & $-0.20 * *$ & $-0.42 * *$ & $-0.28 * *$ & 0.83 & $-2.79 * *$ & $-1.93 * *$ & 0.35 & -0.03 & 0.22 \\
\hline $\mathrm{SE}\left(\mathrm{g}_{\mathrm{ij}}\right) \pm$ & 0.47 & 0.53 & 0.60 & 0.03 & 0.03 & 0.04 & 0.44 & 0.45 & 0.51 & 0.19 & 0.18 & 0.18 \\
\hline
\end{tabular}

Table 2c: Estimates of general combining ability (gca) effects and specific combining ability (sca) effects

\begin{tabular}{|c|c|c|c|c|c|c|c|c|c|c|c|c|}
\hline \multirow{2}{*}{ Parents/crosses } & \multicolumn{3}{|c|}{ ginning percentage $(\%)$} & \multicolumn{3}{|c|}{ seed cotton yield per plant $(\mathrm{g})$} & \multicolumn{3}{|c|}{2.5 per cent span length } & \multicolumn{3}{|c|}{ fibre strength (g/tex) } \\
\hline & CON & GMS & CMS & $\mathrm{CON}$ & GMS & CMS & $\mathrm{CON}$ & GMS & CMS & $\mathrm{CON}$ & GMS & CMS \\
\hline & \begin{tabular}{|l|} 
Pooled \\
\end{tabular} & Pooled & Pooled & Pooled & Pooled & Pooled & Pooled & Pooled & Pooled & Pooled & Pooled & Pooled \\
\hline \multicolumn{13}{|c|}{ 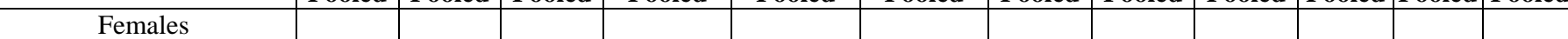 } \\
\hline $76 \mathrm{IH} 20$ & -0.01 & $1.05^{* *}$ & $-1.50 * *$ & $-12.28 * *$ & $-3.01 *$ & $-19.12 * *$ & -0.40 & -0.06 & -0.37 & -0.45 & -0.04 & -0.45 \\
\hline LH 900 & $-1.49 * *$ & $-1.92 * *$ & $-2.49 * *$ & -2.55 & $-15.68 * *$ & $-18.68 * *$ & $-1.39 * *$ & $0.68 * *$ & $1.15 * *$ & -0.30 & -0.26 & $1.39 * *$ \\
\hline PH 93 & $6.68 * *$ & $4.10 * *$ & $4.53 * *$ & $-20.80 * *$ & $-15.46 * *$ & $-7.40 * *$ & -0.52 & -0.31 & $-1.87 * *$ & \begin{tabular}{|l|}
$-0.71 *$ \\
\end{tabular} & $-1.02 *$ & $-0.50 * *$ \\
\hline LRA 5166 & 0.14 & -0.31 & 0.06 & $5.40 * *$ & $-3.08^{*}$ & -1.19 & $0.88 * *$ & -0.05 & -0.27 & 0.26 & -0.15 & 0.35 \\
\hline LRK 516 & $-1.18 * *$ & $-2.29 * *$ & $1.54 * *$ & 2.65 & $12.05 * *$ & $3.00 *$ & 0.20 & 0.30 & -0.25 & 0.54 & $0.94 *$ & $-0.68 *$ \\
\hline $\mathrm{G}(\mathrm{B}) 20$ & $-2.57 * *$ & $-0.89 *$ & $-1.67 * *$ & $30.82 * *$ & $26.01 * *$ & $28.07 * *$ & $-1.17 * *$ & 0.27 & $0.79 * *$ & 0.24 & 0.41 & -0.10 \\
\hline G.Cot. 100 & $-1.56 * *$ & 0.26 & -0.51 & $-3.23 *$ & -0.83 & $15.33 * *$ & $2.41 * *$ & $-0.83 * *$ & $0.88 * *$ & 0.43 & 0.12 & 0.28 \\
\hline $\mathrm{SE}\left(\mathrm{g}_{\mathrm{i}}\right) \pm$ & 0.41 & 0.36 & 0.32 & 1.52 & 1.36 & 1.42 & 0.29 & 0.25 & 0.26 & 0.27 & 0.43 & 0.28 \\
\hline \multicolumn{13}{|l|}{ Males } \\
\hline G.Cot. 10 & -0.12 & 0.25 & -0.45 & -0.71 & $-2.97 * *$ & $-5.43 * *$ & $0.45 * *$ & -0.05 & 0.12 & $0.30 * *$ & -0.06 & $-0.29 *$ \\
\hline DHY 286-1 & 0.12 & -0.25 & 0.45 & 0.71 & 2.97 & $5.43 * *$ & $-0.45 * *$ & 0.05 & -0.12 & $-0.30 * *$ & 0.06 & $0.29 *$ \\
\hline $\mathrm{SE}\left(g_{\mathrm{j}}\right) \pm$ & 0.17 & 0.15 & 0.13 & 0.62 & 0.55 & 0.58 & 0.12 & 0.10 & 0.11 & 0.11 & 0.18 & 0.12 \\
\hline \multicolumn{13}{|l|}{ Crosses } \\
\hline $76 \mathrm{IH} 20$ x G.Cot.10 & 0.64 & $1.10^{* *}$ & 0.51 & -1.76 & $-7.89 * *$ & $-4.71 * *$ & -0.32 & -0.40 & 0.33 & -0.21 & -0.47 & $1.16^{* *}$ \\
\hline 76 IH 20 x DHY 286-1 & -0.64 & $-1.10 * *$ & -0.51 & 1.76 & $7.89 * *$ & $4.71 * *$ & 0.32 & 0.40 & -0.33 & 0.21 & 0.47 & $-1.16^{* *}$ \\
\hline LH $900 x$ & 0.22 & $-1.74 * *$ & -0.21 & $-9.05 * *$ & $-17.66^{* *}$ & $-3.74 *$ & 0.26 & $-1.25 * *$ & -0.32 & -0.52 & -0.50 & 0.29 \\
\hline LH 900 x DHY 286-1 & -0.22 & $1.74 * *$ & 0.21 & $9.05 * *$ & $17.66 * *$ & $3.74 *$ & -0.26 & $1.25 * *$ & 0.32 & 0.52 & -0.50 & -0.29 \\
\hline PH 93 x G.Cot.10 & $-1.34 * *$ & $0.86^{*}$ & 0.69 & $6.05 * *$ & $3.23 *$ & $-3.29 *$ & -0.91 & $0.58^{*}$ & $-1.34 * *$ & -0.28 & -0.23 & $-1.28 * *$ \\
\hline PH 93 x DHY 286-1 & $1.34 * *$ & $-0.86^{*}$ & -0.69 & $-6.05 * *$ & $-3.23 *$ & $3.29 *$ & 0.91 & $-0.58 *$ & $1.34 * *$ & 0.28 & 0.23 & $1.28 * *$ \\
\hline LRA 5166 x G.Cot. 10 & $2.77 * *$ & 0.67 & -0.15 & $7.87 * *$ & $12.93 * *$ & $6.66 * *$ & 0.01 & 0.20 & 0.51 & $-0.82 * *$ & $1.09 *$ & $-1.62 *$ \\
\hline LRA 5166 x DHY 286-1 & $-2.77 * *$ & -0.67 & 0.15 & $-7.87 * *$ & $-12.93 * *$ & $-6.66 * *$ & -0.01 & -0.20 & -0.51 & $0.82 * *$ & -1.09 & $-0.66^{*}$ \\
\hline LRK 516 x G.Cot.10 & \begin{tabular}{|l|}
$-0.91 *$ \\
\end{tabular} & 0.12 & $1.44 * *$ & $-10.63 * *$ & $11.44 * *$ & $-8.36 * *$ & $1.04 * *$ & $0.64 *$ & 0.50 & $0.77 * *$ & -0.30 & $0.66^{*}$ \\
\hline LRK 516 x DHY 286-1 & $0.91 *$ & -0.12 & $-1.44 * *$ & $10.63 * *$ & $-11.44 * *$ & $8.36 * *$ & $-1.04 * *$ & $-0.64 *$ & -0.50 & $-0.77 * *$ & 0.30 & $0.66^{* *}$ \\
\hline G(B) 20 x G.Cot. 10 & $1.19 * *$ & $1.46^{* *}$ & $-1.46^{* *}$ & $3.42 *$ & $10.79 * *$ & $12.58 * *$ & 0.15 & 0.02 & -0.21 & 0.08 & -0.12 & $0.77 *$ \\
\hline G(B) $20 \times$ DHY 286-1 & $-1.19 * *$ & $-1.46^{* *}$ & $1.46 * *$ & $-3.42 *$ & $-10.79 * *$ & $-12.58 * *$ & -0.15 & -0.02 & 0.21 & -0.08 & 0.12 & $-0.77 *$ \\
\hline G.Cot.100 x G.Cot.10 & $-2.57 * *$ & $-2.46^{* *}$ & $-0.82^{*}$ & $4.09 *$ & $10.04 * *$ & 0.85 & -0.22 & 0.21 & $0.54 *$ & 0.44 & 0.53 & 0.34 \\
\hline G.Cot.100 x DHY 286-1 & $2.57 * *$ & $2.46^{* *}$ & $0.82 *$ & $-4.09 *$ & $-10.04 * *$ & -0.85 & 0.22 & -0.21 & $-0.54 *$ & -0.44 & -0.53 & -0.34 \\
\hline $\operatorname{SE}\left(g_{i j}\right) \pm$ & 0.41 & 0.36 & 0.32 & 1.52 & 1.36 & 1.42 & 0.29 & 0.25 & 0.26 & 0.27 & 0.43 & 0.28 \\
\hline
\end{tabular}

Table 3: Best parents, best general combiners and best specific combiners for different characters in pooled analysis

\begin{tabular}{|c|c|c|c|c|}
\hline S. No. & Character & Best parents per se & Best general combiners & Best specific combiners \\
\hline 1 & Days to $50 \%$ flowering & $\mathrm{G}(\mathrm{B}) 20$ & $\begin{array}{c}\text { LRK } 516 \\
\text { PH } 93 \\
\text { G.Cot.10 }\end{array}$ & CMS-LH 900 x Dhy 286-1 \\
\hline 2 & Plant height & $\begin{array}{c}\text { LRK } 516 \\
\text { LRA } 5166 \\
\text { G(B) } 20\end{array}$ & $\begin{array}{c}\text { LRK } 516 \\
\text { LH } 900 \\
\text { LRA } 5166\end{array}$ & CMS- G(B) 20 x DHY 286-1 \\
\hline 3 & No.of monopodia/ plant & $\begin{array}{c}\text { DHY 286-1 } \\
\text { LRA } 5166 \\
\text { LH } 900 \\
\end{array}$ & $\begin{array}{c}\text { LRK } 516 \\
\text { G.Cot.100 } \\
\text { LRA } 5166 \\
\end{array}$ & CMS-LRK 516 x DHY 286-1 \\
\hline 4 & No.of sympodia / plant & $\begin{array}{c}76 \text { IH } 20 \\
\text { PH } 93 \\
\text { G.Cot.10 }\end{array}$ & $\begin{array}{l}\text { G(B) } 20 \\
\text { LRK } 516 \\
\text { G.Cot. } 10\end{array}$ & CMS- G.Cot.100 x G.Cot.10 \\
\hline 5 & No.of bolls per plant & G.Cot.10 & PH 93 & CMS- G(B) 20 x G.Cot.10 \\
\hline
\end{tabular}




\begin{tabular}{|c|c|c|c|c|}
\hline & & $\begin{array}{c}\text { LRA } 5166 \\
\text { G(B) } 20\end{array}$ & $\begin{array}{c}\text { G.Cot. } 100 \\
\text { G(B) } 20\end{array}$ & \\
\hline 6 & Boll weight & $\begin{array}{c}\text { LRK } 516 \\
\text { G(B) } 20 \\
\text { DHY 286-1 }\end{array}$ & $\begin{array}{c}\text { G.Cot. } 100 \\
\text { G(B) } 20 \\
\text { LRK } 516\end{array}$ & CMS-G.Cot. 100 x G.Cot.10 \\
\hline 7 & No.of pods per boll & $\begin{array}{c}76 \text { IH } 20 \\
\text { G.Cot. } 10 \\
\text { LRA } 5166\end{array}$ & $\begin{array}{c}\text { G(B) } 20 \\
\text { G.Cot. } 100 \\
\text { DHY 286-1 }\end{array}$ & CMS-G.Cot. 100 x G.Cot. 10 \\
\hline 8 & Seed index & $\begin{array}{c}\text { G.Cot. } 100 \\
\text { G(B) } 20 \\
\text { G.Cot. } 10\end{array}$ & $\begin{array}{c}\text { G.Cot. } 100 \\
\text { G(B) } 20 \\
\text { DHY 286-1 }\end{array}$ & CMS-LRA 5166 x G.Cot.10 \\
\hline 9 & Ginning percentage & $\begin{array}{c}\text { PH 93 } \\
\text { LRK 516 } \\
\text { DHY 286-1 }\end{array}$ & $\begin{array}{c}\text { PH 93 } \\
\text { LRK 516 } \\
\text { DHY 286-1 }\end{array}$ & CMS-G(B) 20 x DHY 286-1 \\
\hline 10 & Seed cotton yield/plant & $\begin{array}{l}\text { G(B) } 20 \\
\text { G.Cot. } 10 \\
\text { LRK } 516\end{array}$ & $\begin{array}{c}\text { G(B) } 20 \\
\text { G.Cot. } 100 \\
\text { DHY 286-1 }\end{array}$ & CMS-G(B) 20 x G.Cot.10 \\
\hline 11 & $2.5 \%$ Span Length & $\begin{array}{c}\text { G.Cot. } 100 \\
\text { LRK } 516 \\
\text { G(B) } 20\end{array}$ & $\begin{array}{c}\text { LH } 900 \\
\text { G.Cot. } 100 \\
\text { G(B) } 20\end{array}$ & CMS-PH 93 x DHY 286-1 \\
\hline 12 & Fibre strength & $\begin{array}{c}\text { DHY 286-1 } \\
\text { G.Cot.100 } \\
\text { LRK } 516\end{array}$ & $\begin{array}{c}\text { LH } 900 \\
\text { DHY 286-1 } \\
\text { LRA } 5166\end{array}$ & CMS-PH 93 x DHY 286-1 \\
\hline
\end{tabular}

\section{References}

1. Falconer DS. 'Introduction to quantitative genetics'. Oliver and Boyd; Edinburgh, 1960, 365.

2. Gupta MP, Singh RB. Combining ability in upland cotton- ginning and fibre characters. Indian $\mathrm{J}$ Genet., 1974; 34:422-426.

3. Gururajan KN, Basu AK. Heterosis and combining ability in medium staple cotton. J Indian Soc. Cott. Improv. 1992; 17(1):17-22.

4. Jagtap DR, Kolhe AK. Diallel analysis for combining ability in upland cotton (G. hirsutum L.). J Indian Soc. Cott. Improv. 1993; 7(2):206-211.

5. Kempthorne O. An introduction to genetic statistics John willey and sons, New York, 1957, 453-471.

6. Modi ND, Patel JC, Patel DH, Maisuria AT, Patel UG. Heterosis and combining ability for yield and fibre quality in desi cottons. J Indian Soc. Cott. Improv. 1999a; 24(2):132-134.

7. Modi ND, Patel, UG, Patel JC, Maisuria AT. General and specific combining ability for major yield components in diploid cotton. J Indian Soc. Cott. Improv. 1999b; 24(2):129-131.

8. Patel GS, Pethani KV. Studies on heterosis, combining ability and phenotypic stability in cotton ( $G$. arboreum L.). The unpublished Ph.D. thesis, submitted to G.A.U., S.K. Nagar, 1995.

9. Patel JC, Patel RH, Patel DH, Patel MV, Modi ND. Asiatic hybrids cotton performance through GMS: Heterosis and combining ability. Paper presented at National Seminar on "Increasing production and productivity of irrigated cotton for $21^{\text {st }}$ century" held at M.P.K.V., Rahuri on $14^{\text {th }}$ and $15^{\text {th }}$ September, 1997.

10. Patel UG, Mehta NP. Studies on heterosis, combining ability and stability of performance in cotton ( $G$. herbaceum L.). Unpublished Ph.D. thesis submitted to G.A.U., S.K.Nagar, 1985.

11. Pathak RS, Kumar P. Combining ability studies in upland cotton. G. hirsutum L. Zemt. Chrift for pflanzenchtung, (Fide : Pl. Breed. Abst., 46 : 780). 1975; 75:297-370.

12. Singh TH, Randhawa IS, Singh M. Combining ability studies for lint yield and its components over environments in upland cotton. J Indian Soc. Cott. Improv. 1988; 13(1):11-15.
13. Vadodaria KV, Patel RH. Genetic analysis of qualitative and quantitative traits in upland cotton (G. hirsutum L.). Unpublished Ph.D. thesis submitted to G.A.U., S.K. Nagar, 1995.

14. Verma SS, Lather BPS, Verma U. Line $\mathrm{x}$ tester analysis for yield and its components in upland cotton. J Cott. Res. and Dev. 1991; 5(2):90-95. 